\title{
PLUM (PRUNUS ROSSICA EREM.) FRUIT FIELD AND LABORATORY RESEARCES DEPENDING ON THE SCION-STOCK COMBINATIONS
}

\author{
Svetlana Motyleva, Galina Upadysheva, Ivan Kulikov, Mikhail Upadyshev, Sergey Medvedev, \\ Dariya Panischeva
}

\begin{abstract}
The results of the field observations and biochemical researches of plum (Prunus rossica Erem.) fruits grown in the garden of intensive type with agrogenic soil in row spacing are presented in the article. The fruits of plum breeds Kubanskaya kometa and Naidena were gathered from the trees grafted on different stocks. The influence of the stock on the trees productivity, the fruit weight and biochemical structure of the plum fruits were studied. Basic chemical analyses, ascorbic acid concentration, antioxidant activity and fruit ash content were determined. The variation limits of the parameters under study depending on the used stock were shown. The best degustation evaluation parameters were found at the combinations of Kubanskaya kometa on stocks OPA-15-2 and Novinka, Naidena on stocks OPA-15-2 (more than 4,5 points). The high positive correlation $(r=0.92)$ was marked between soluble solids and sugars content. The researches about the stock influence on the plum fruits titratable acidity change we have not found. The correlation between AA and ascorbic acid content in the fruits was determined $(\mathrm{r}=0.7)$. The decreasing row of the elements content in the plum fruits ash is the following: $\mathrm{K}>\mathrm{P}>\mathrm{Mg}>\mathrm{Ca}>\mathrm{Mo}>\mathrm{Cu}>\mathrm{S}>\mathrm{Ni}>\mathrm{Fe} \approx \mathrm{Si}>\mathrm{Mn}$. The proportion of $\mathrm{K}$ is from 18.67 (Naidena/OPA-15-2) to 27.48 (Kubanskaya kometa/Novinka); P from 3.35 (Kubanskaya kometa/seedlings $P$. cerasifera Ehrh. to 6.39 (Kubanskaya kometa/Novinka), Mg from 1.11 (Naidena/OPA-15-2) to 2.43 (Naidena/seedlings $P$. cerasifera Ehrh.) and Ca from 0.39 (Naidena/13-113) to 1.85 (Naidena/OPA-15-2) mass \% respectively. The proportion of the rest elements is not more than 1 mass \%. Under the OPA-15-2 stock influence the trees productivity and the single fruit weight increased, soluble solids, sugars and ascorbic acid concentration in the fruit in comparison with standard stock by the seedling rootstock of alycha (Prunus cerasifera Ehrh. seedlings). While ingrafting by Novinka stocks the parameters under study decreased.
\end{abstract}

Keywords: plum; clonal stock; scion-stock combinations; biochemical structure of fruit

\section{INTRODUCTION}

One of the most perspective plum breeds cultivated on the European territory of Russia is plum Russkaya (Prunus rossica Erem.). The first breeds were received by the member of the Academy of Siences G. V. Petrov on Krymskaya EBS ARIR (Krandodarskiy Krai) as the result of cross-species hybridization of breed Skoroplodnaya (Prunus ussuriensis L.) and alycha breed Pionerka (Prunus cerasifera Ehrh.) (Eremin, 2003). At the present time thanks to winter-hardy breeds Prunus rossica Erem. they are cultivated not only in the southern areas, but in the Central region of Russia (Upadysheva, 2017). It is appreciated for the high eating qualities of the fruit, their curative and dietic properties (Motyleva et al., 2017). Plum fruit are rich in organic mineral substances: monoand disaccharides, pectin, vitamins, flavonoids and other biologically active substances (Kukurová et al., 2015; Kulichová et al., 2016).

The researches of the totally different fruit antioxidant ability measurements showed that plums have one of the highest antioxidant activities (Imeh and Khokhar, 2002). Among the molecules that show antioxidant activity in plums it was discovered that the phenolic compounds contribution is essentially higher than vitamin $\mathrm{C}$ and carotenoids contribution (Gil et al., 2002). For the plum reproduction and the intensive gardens creation the clonal stocks are used (Dekena et al., 2017). As our experiments with sweet cherry show the stock influences the grafted plants development and metabolism determining the harvest quality (Upadysheva et al., 2018). For the plums the question of the stock influence on the fruit quality is not studied enough. The plum hybrid rootstock forms either are self-sterile or have small non-edible fruit with 
bitterness. This may cause the deterioration of grafted scion fruit taste and properties. The purpose of our work is to study the productivity and plum (Prunus rossica Erem.) fruit quality depending on the stock-scion combination.

\section{Scientific hypothesis}

The productivity, the plum (Prunus rossica Erem.) fruit quality and their biochemical composition depending on the stock-scion combination are not studied enough. We have checked the influence of the stock on the formation of productivity, quality and nutritional value of Prunus rossica Erem fruit Kubanskaya kometa and Naidena grown in Moscow region conditions. We supposed that on the base of the field and laboratory experiments the optimal stock for each breed that will provide the high productivity and valuable biological active substances accumulation in the plum fruit in comparison with the traditional seedling rootstock will be found.

\section{MATERIAL AND METHODOLOGY}

The field researches were held in 2017-2018 on the experimental plum Prunus rossica Erem. plantations of Federal State Budgetary Scientific Institution "All-Russion Horticultural Institute for Breeding. Agrotechnology and Nursery", Moscowregion (Figure 1). The plantation overall area is 0.5 ha. The garden of intensive type is set out using the pressed scheme. The soil in the row spacing is agrogenic. The experimental researches object was the fruit of plum Kubamskaya kometa and Naidena breeds grafted on four stocks: 13-113, Novinka, OPA-15-2, Prunus cerasifera Ehrh alycha seedling (standard). Under study there were 8 scion-stock combinations totally, not less than 6 trees in each combination were studied. The biochemical researches were held in the Laboratory of Physiology and Biochemistry of Federal State Budgetary Scientific Institution "All-Russian Horticultural Institute for Breeding, Agrotechnology and Nursery“".
The determination of the productivity and fruit weight and the sensor evaluation

In the period of fruit ripening the trees productivity was determined by the fruitage weighing from each tree in five-time repetition. The average fruit weight and the stone-fruit weight relation were determined by the weighing of 100 fruits in three-time repetition. The sensor evaluation was fulfilled by the group of high qualified specialists for the evaluating products. They estimated three main quality parameters: taste (sweet, sour, with bitterness), after taste and fruit external appearance - the form, colour, the surface condition.

\section{Chemicals}

All chemical substances chosen for the analysis were of analytical sort and were bought from Sigma Aldrich (USA).

\section{Sample preparation}

From average $1000 \mathrm{~g}$ probe $100 \mathrm{~g}$ fruit without stone were prepared and extracted by double-distilled water (to determine antioxidant activity) and metaphosphoric acid (for ascorbic acid determination) with the help of highspeed homogenizer (10 $000 \mathrm{rpm}, 1 \mathrm{~min}$, UltraTurrax T25 Basic, IKA). After centrifugation at $4000 \mathrm{~g}$ (Sigma, Germany) within $10 \mathrm{~min}$ the supernatant was used for measuring. The extraction as well as the measurements were held in three-time repetition.

\section{Basic chemical analyses}

Studied biochemical parameters: dry matter - by drying samples to constant weight at $\mathrm{t}=100{ }^{\circ} \mathrm{C}$. Titratable acidity. Total titratable acidity (TTA) - titration with $10 \mathrm{~N}$ $\mathrm{NaOH}$ - was estimated by alkalimeter and expressed in g. $\mathrm{kg}^{-1}$ malic acid equivalent of fresh matter. The soluble solids content (SSC) was expressed by the index of refraction $\left({ }^{\circ} \mathrm{Bx}\right)$. Content of sugars (glucose, sucrose, fructose) by methods of Bertrand (Ermakov, Arasimovich and Jarosh, 1987).

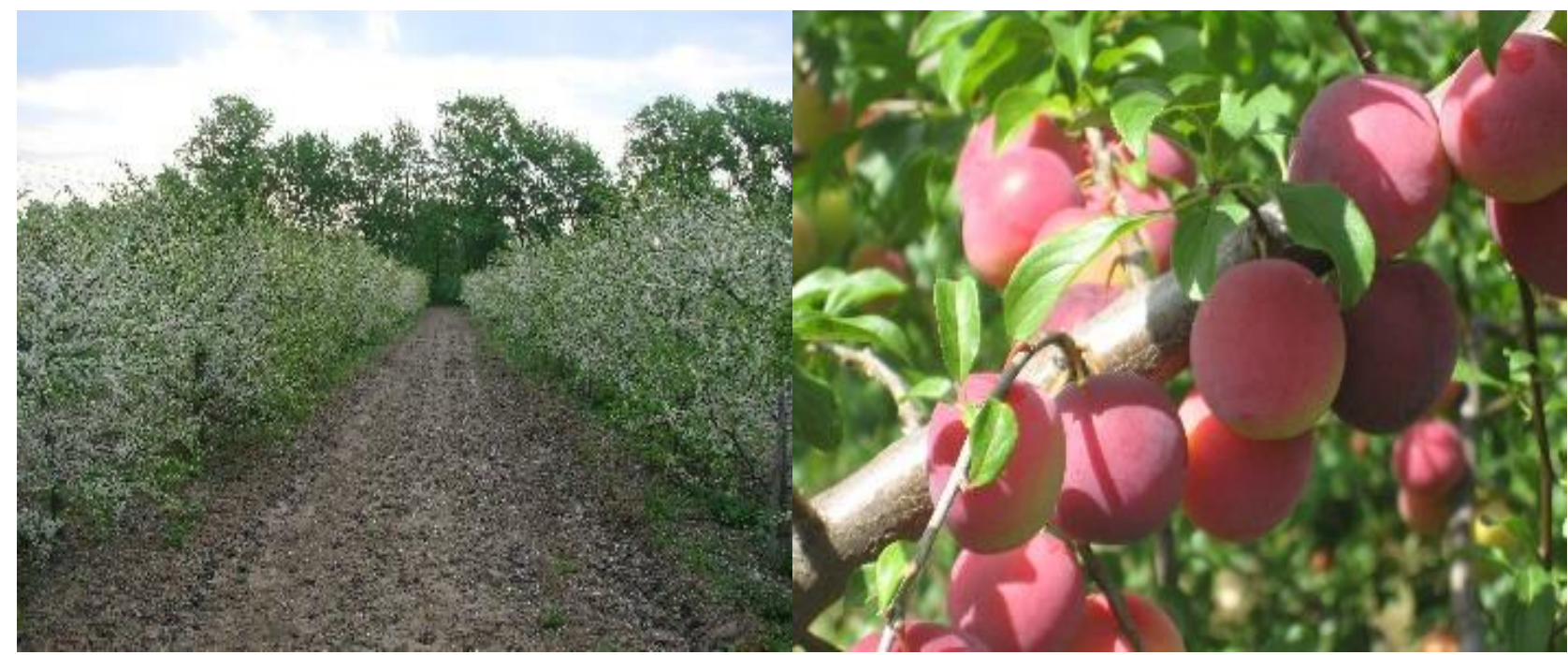

Figure 1 Plum plantations: Left - blossoming garden, row spacing - agrogenic soil. Right - fruitage, Kubanskaya kometa breed. 


\section{Ascorbic acid (AsA) determination}

Ascorbic acid determination was held using HELC method (Stan et al., 2014), the chromatograph KNAUER (Germany) was used. Chromatoghraphic conditions: HELC column Silasorb C18 (5 mkm), 150 x $4.0 \mathrm{~mm}$ (Biohimmac, Russia), the column temperature is $25^{\circ} \mathrm{C}$, flow speed $1.0 \mathrm{~mL} \cdot \mathrm{min}^{-1}$, the detector UV, the wave length $1=251 \mathrm{~nm}$, the mobile phase $\mathrm{MeOH}$ : water $-5: 95$ (r./r.), aliquote for injections $20 \mathrm{mkL}$, the retention time $\mathrm{Rt}=$ $4.4 \mathrm{~mm}$.

\section{Antioxidant activity (AA) determination}

Antioxidant activity was measured by the BrandWilliams et al. (1995) method using a compound DPPH ${ }^{*}$ (2.2-diphenyl-1-pikrylhydrazyl). The spectrophotometer Thermo Helios Y (Thermo Fisher Scientific, made in England) was used. The homogenized by the distilled water samples were put on the shaker Lab-PU-01 (Russia) for 8 hours, and then they were filtered, and the antioxidant activity was measured in 10 minutes after interaction between the extract and reagent at wavelength $515 \mathrm{~nm}$. The calculation of antioxidant activity values was fulfilled using the formula: Where:

$$
\text { Inhibiting DPPH }=(\mathrm{AC}-\mathrm{AAt})=\mathrm{AC} / 100(\%),
$$

AC - DPPH solution absorption; AAt - absorption at the antioxidant presence.

Three-time repetition.

\section{EDS - analysis}

The chemical composition of the basic ash components (Na, P, S, K, Mn, Fe, Mg, Ca, Al, Si, Cl, Zn, Se, Mo) was determined by the method of energy dispersive spectrometry (ESD) on the analytical raster electron microscope JEOL JSM 6090 LA. The microscope solution is $4 \mathrm{~nm}$ at accelerating voltage $20 \mathrm{kV}$ (secondary electrons image), zooming is from $\times 10$ till $\times 10000$. While performing the elemental analysis the working distance (WD) is $10 \mathrm{~mm}$. Energy-dispersive spectrometer allows to carry out the quantitative X-ray microanalysis with the desired analysing area: in a point or areally, and to receive the maps of elements allocation. X-ray microanalysis data are presented in the form of standard protocols which contain the microstructure picture of the sample under

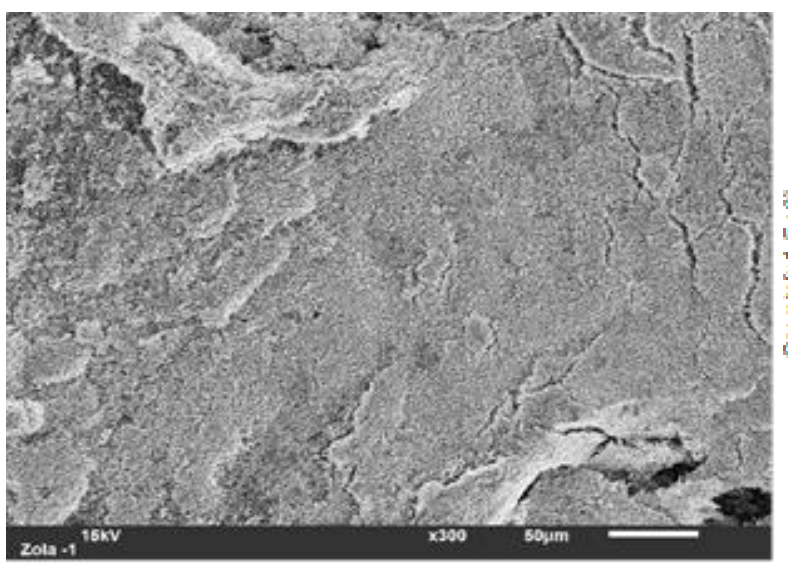

A study, the table of the data in weighting and atomic correlation, spectra and histograms. The spectrum example is shown in Figure 2.

Taking into consideration the spectrum lines intensity the concentration of the desired element can be determined. The fractional accuracy of the chemical analysis is spread in the following way: at the element concentration from 1 till $5 \%$ the accuracy is less than $10 \%$; from 5 till $10 \%$ the accuracy is less than 5\%; at the element concentration more than $10 \%$ the accuracy is less than $2 \% .100$ ash areas of each sample were studied. The local analysis is $3 \mathrm{~mm}$, the scanned area is not less than $12 \mathrm{um}$.

\section{Statistic analysis}

All analyses were three-time repetition. Results were expressed as mean values $(\mathrm{n}=3) \pm$ standard deviation $(S D)$.

To determine the differences - significance between the data one-way and two-factor experience ANOVA test was used $(p<0.05)$ via the program Statgraphics Centurion XV (USA).

\section{RESULTS AND DISCUSSION}

As a result, it was determined that the plum trees productivity at average for the period of 5 years was $14.2 \mathrm{~kg} / \mathrm{tr}$. and depending on the stock varied from $9.2 \mathrm{~kg} / \mathrm{tr}$. (Naidena on seedlings) to $21.8 \mathrm{~kg} / \mathrm{tr}$. (Kubanskaya kometa on OPA-15-2). Higher than the average value this parameter was at the trees of scion Kubanskaya kometa grafted on the stocks 13-113 and Novinka. It should be mentioned that scion Novinka productivity depending on the stock varied in less degree (Table 1). The influence of stock on the productivity of plum trees was noted in (Grzyb, Sitarek, and Kozinski, 1998; Magyar and Hrotkó, 2006).

Scions under study belong to large-fruited group with the fruit weight more than $30 \mathrm{~g}$. The single fruit weight of scion Kubanskaya kometa with average value of $32 \mathrm{~g}$ depending on the stock was changing from $29.5 \mathrm{~g}$ (seedlings) $34.8 \mathrm{~g}$ (OPA-15-2). The fruits of the scions under study were significantly bigger because of stocks OPA-15-2 and Novinka influence. Scion Kubanskaya kometa stone separated from the flesh badly, its portion in the fruit weight was $7 \%$ at average with variation depending on

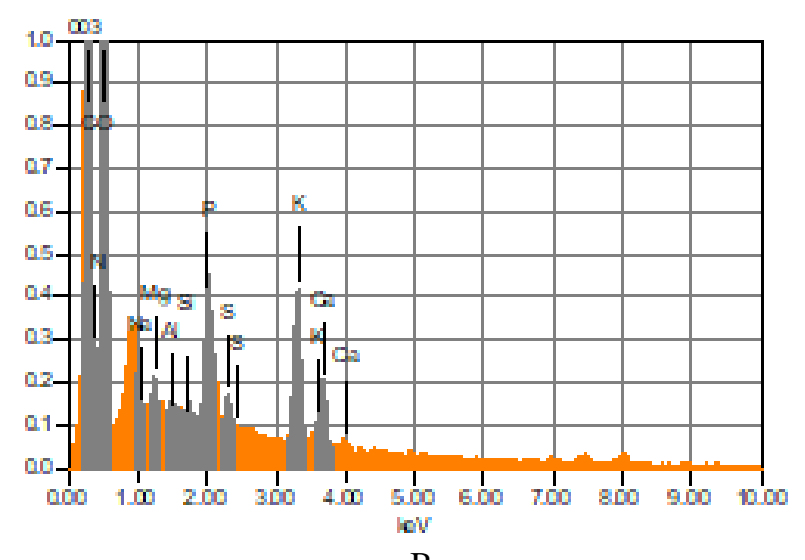

B

Figure 2 The microstructure picture of the sample under study (A) and the general view of the X-ray spectrum lines (B). 
Table 1 The productivity, fetal mass and organoleptic estimation of Prunus rossica Erem. fruits depending on the stock at average in $2017-2018$.

\begin{tabular}{|c|c|c|c|}
\hline \multirow[b]{2}{*}{ Stock-scion combination } & \multicolumn{3}{|c|}{ Parameters under study } \\
\hline & $\begin{array}{c}\text { Productivity } \\
\text { (kg/tree) }\end{array}$ & $\begin{array}{c}\text { Average fruit Weight } \\
(\mathrm{g} \pm S D)\end{array}$ & $\begin{array}{c}\text { Degustation evaluation, } \\
\text { point }\end{array}$ \\
\hline $\begin{array}{l}\text { Kubanskaya kometa/ } \\
13-113\end{array}$ & $16.8 \pm 2.41$ & $31.22 \pm 0.41$ & 4.1 \\
\hline $\begin{array}{l}\text { Kubanskya kometa/ } \\
\text { Novinka }\end{array}$ & $19.4 \pm 1.19$ & $32.33 \pm 0.44$ & 4.6 \\
\hline $\begin{array}{l}\text { Kubanskaya kometa/ } \\
\text { OPA-15-2 }\end{array}$ & $21.8 \pm 2.54$ & $34.82 \pm 0.51$ & 4.8 \\
\hline $\begin{array}{l}\text { Kubanskaya kometa/ } \\
\text { Seedlings }\end{array}$ & $11.7 \pm 1.87$ & $29.54 \pm 0.31$ & 4.0 \\
\hline P.cerasifera Ehrh & $10.9 \pm 2.07$ & $28.64 \pm 0.61$ & 4.1 \\
\hline Naidena/ 13-113 & $11.8 \pm 2.17$ & $32.01 \pm 0.41$ & 4.3 \\
\hline Naidena/Novinka & $12.3 \pm 1.25$ & $32.53 \pm 0.61$ & 4.5 \\
\hline Naidena/OPA-15-2 & $9.2 \pm 0.87$ & $28.07 \pm 0.73$ & 4.0 \\
\hline
\end{tabular}

from $6.8 \%$ (Novinka) to $7.5 \%$ (seedlings).

At scion Naidena the stone was slightly smaller, separated from the flesh better and was nearly $6 \%$ for all stock-scion combination. According to the degustation results the fruits of the scions under study were characterized by the harmonized sore-sweet taste and smell (4.0 - 4.8 points), no taste deterioration and bitterness were observed on either of the stocks. The best degustation evaluation parameters were found at the combinations of Kubanskaya kometa on stocks OPA-15-2 and Novinka, Naidena on OPA-15-2 (more than 4.5 points). The plum ( $P$. rossica Erem.) fruits were characterized by the high content of soluble solids and sugars which depended on the stock-scion combination. The solutable solids content variated from 11. $2 \%$ (Kubanskaya kometa on seedlings) to $15.2 \%$ (Naidena on OPA-15-2) at average value of $12.9 \%$ (Figure 3.).

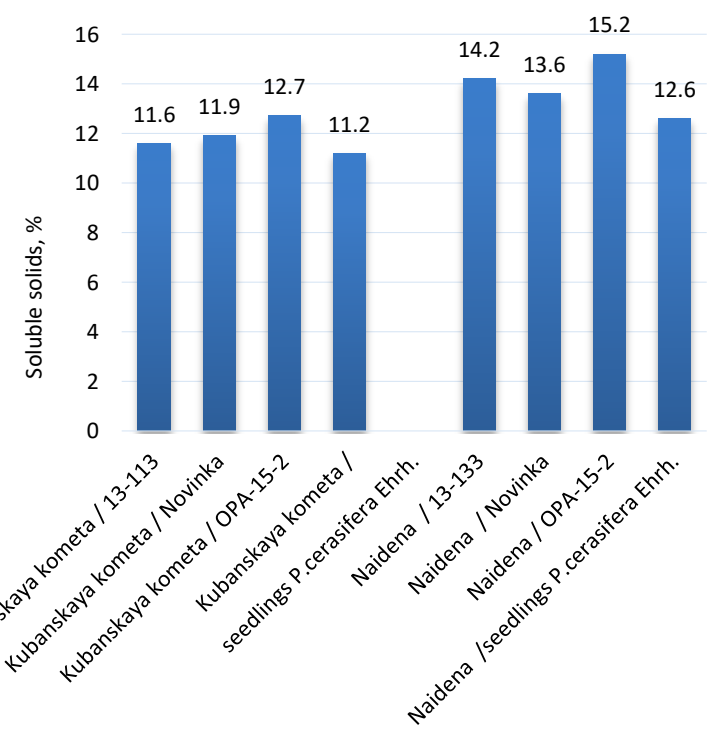

Figure 3 Soluble solids content in plum fruits.
However, there is conflicting evidence that confirm that the solids soluble content/titratable acidity ratio weren't affected by soil type or rootstock (Ratoa et al.,2008). The sugars content in the fruits was within $7.2-10.0 \%$. The sugars higher accumulation was found at scion-stock combinations Naidena on OPA-15-2 (10\%) and on Novinka (9.3\%) (Figure 4).

The high positive correlation $(\mathrm{r}=0.92)$ was marked between soluble solids and sugars content. While evaluating the stock influence it should be noted that the soluble solids content on stock OPA-15-2 is on $13-20 \%$ higher in comparison with alycha standard seedlings. The received data correlate with Hatton et al. (2015) researching results about the stock influence on the plum trees productivity and the apricot fruits productivity and quality (Milosevic et al., 2011) and plum fruits biochemical parameters change (Świerczyński and Stachowiak, 2009).

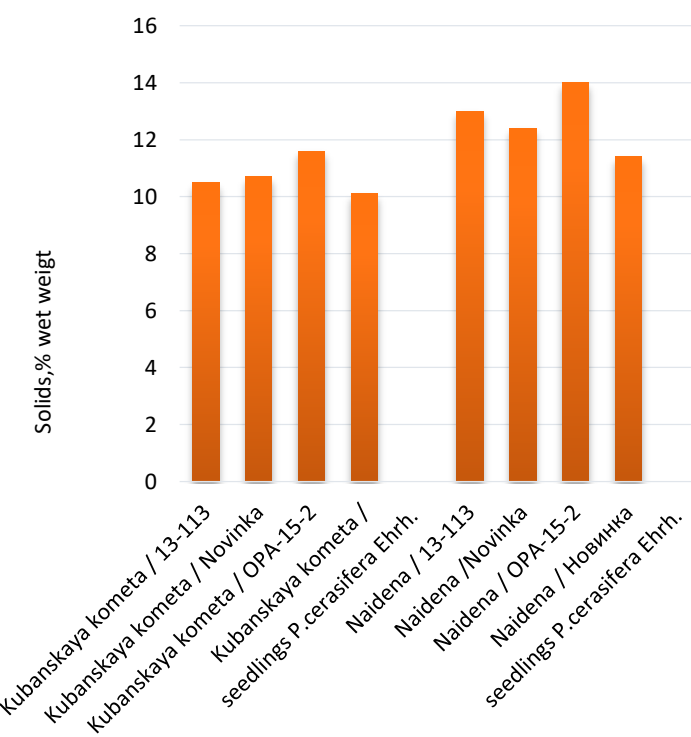

Figure 4 Solids content in plum fruits of Prunus rossica Erem., depending on the stock at average in $2017-2018$. 


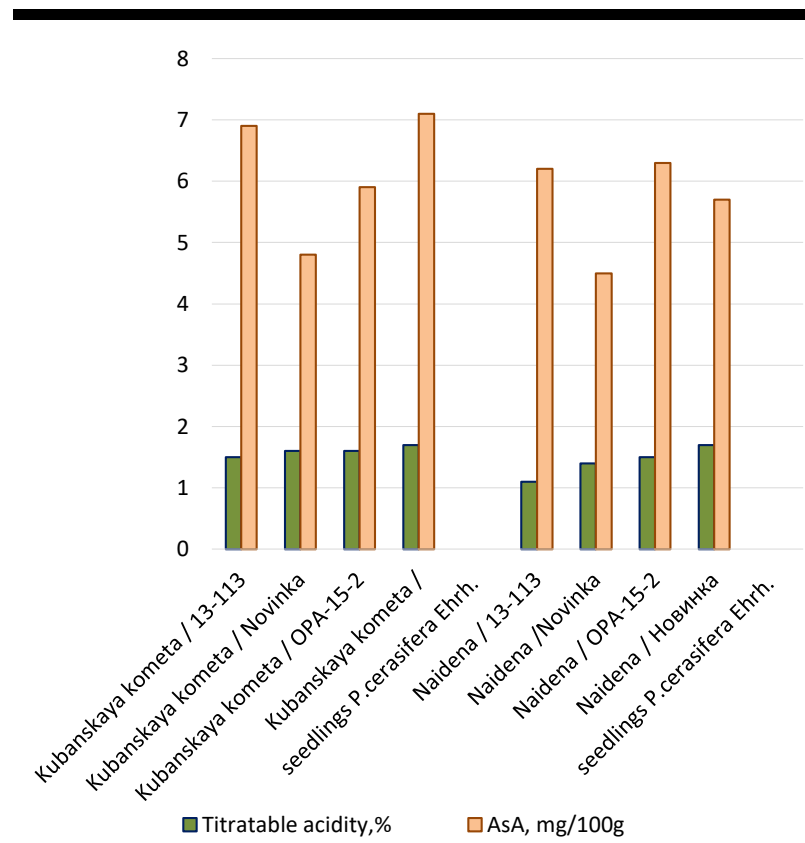

Figure 5 Titratable acidity and ascorbic acid content in plum fruits of Prunus rossica Erem. depending on the stock at average in $2017-2018$.
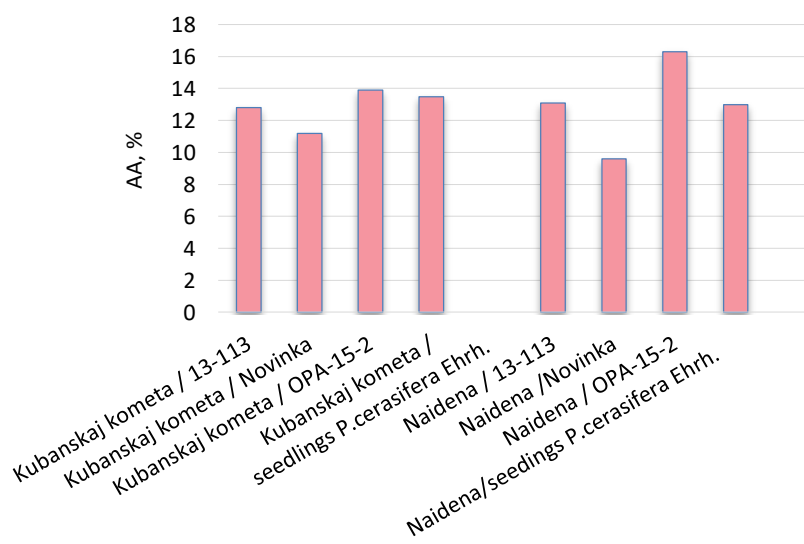

Figure 6 Antioxidant activity in plum fruits of Prunus rossica Erem. depending on the stock at average in 2017 $-2018$.

Organic acids determined the plum fruits titratable acidity. The scion-stock combination under study showed the titratable acidity variation from 1.1 to $1.7 \%$. The maximum values of the plum fruits titratable acidity (1.6 $1.7 \%$ ) were determined for the scion Kubanskaya kometa on the stocks Novinka, OPA-15-2 and on the seedlings $P$. cerasifera Ehrh. Studies performed by Milošević and Milošević (2012) showed that the influence of rootstocks on most of the analysed quality attributes plum was variable because strong and complex interactions, rootstock $\times$ cultivar, rootstock $\times$ year and cultivar $\times$ year, were observed. Several traits, such as yield, soluble solids/acid content ratio and total sugars/acid content ratio, seem to be harder conditioned in rootstocks. For the scion Naidena on the same stocks the titratable acidity values were maximum $(1.4-1.7 \%)$. On the seedlings the influence on the fruits acidity was expressed by some increase of titratable acidity value and was marked at the level of $1.7 \%$ for both scions, the titratable acidity minimum value for the both scions was marked on the stock 13-113 and was marked at the level of $1.5 \%$ (Kubanskaya kometa) and 1.1\% (Naidena) (Figure 5). The received titratable acid values are lower than in the fruits Prunus spinosa L., as it is described in the paper Erturka, Ercislib and Tosun (2009). The researches about the stock influence on the plum fruits titratable acidity change we have not found. AsA content in plum fruits is not relatively high - not more than $7,1 \mathrm{mg} / 100 \mathrm{~g}$. At average AsA content in scion Kubanskaya kometa fruits is $6.2 \mathrm{mg} \cdot 100 \mathrm{~g}^{-1}$, in scion Naidena fruits $-5.7 \mathrm{mg} \cdot 100 \mathrm{~g}^{-1}$.

It should be mentioned that on the stocks 13-113 and Novinka both scions accumulate the same AsA content. We could not find any papers about the stock influence on AsA content as well, however, the received quantites correspond to the literary data (Gil et al., 2002). The fruits total AA that determines their value for the functional nutrition was nearly $13 \%$ depending on the used stock. It varied greatly at scion Naidena: from $9.6 \%$ (Novinka) to 16.3\% (OPA-15-2), Figure 6. Plums are characterized by a relatively high content of antioxidants. Our results are consistent with those of Najafabad and Jamei (2014). We did not find in the scientific literature information on the effect of stock on the antioxidant activity of plum fruits. But when analyzing the antioxidant activity of cherry plum leaves, we found a significant effect of the stock (Upadysheva and Motyleva, 2019).The correlation between AA and ascorbic acid content in the fruits was determined $(r=0.70)$. Kalt et al., (1999) reported that the ascorbate content and the antioxidant activity, being negatively correlated $(\mathrm{r}=-0.80)$ for strawberries, raspberries and high- and low-bush blueberries. High correlation between antioxidant activity and vitamin $\mathrm{C}$ was likely to be found only in fruits that contain high vitamin C such as citrus fruits (Gardner et al., 2000). The high nutritional value of plum fruits is determined not only by the organic bioactive substances content, such mineral components as $\mathrm{K}, \mathrm{Na}, \mathrm{Ca}, \mathrm{Mg}$ play an important role (Agbede and Ibitoye, 2007; Motyleva, Simonov and Kulikov, 2017). We analysed the content of 11 elements in the plum fruits ash $-\mathrm{K}, \mathrm{P}, \mathrm{Mg}, \mathrm{Ca}, \mathrm{Mo}, \mathrm{Si}, \mathrm{Mn}, \mathrm{Fe}, \mathrm{Ni}$, $\mathrm{Cu}$ and $\mathrm{S}$ (shown in Table 2). $\mathrm{K}$ was a prevailing element. The decreasing row of the elements content in the plum fruits ash is the following: $\mathrm{K}>\mathrm{P}>\mathrm{Mg}>\mathrm{Ca}>\mathrm{Mo}>\mathrm{Cu}>\mathrm{S}>\mathrm{Ni}>\mathrm{Fe} \approx \mathrm{Si}>\mathrm{Mn}$. The proportion of $\mathrm{K}$ is from 18.67 (Naidena/OPA-15-2) to 27.48 (Kubanskaya kometa/Novinka); P from 3.35 (Kubanskaya kometa/seedlings $P$. cerasifera Ehrh. to 6.39 (Kubanskaya kometa/Novinka), Mg from 1.11 (Naidena/OPA-15-2) to 2.43 (Naidena/seedlings $P$. cerasifera Ehrh.) and Ca from 0.39 (Naidena/13-11) to 1.85 (Naidena/OPA-15-2) mass \% respectively. 
Table 2 The elemental composition of fruit joint of Prunus rossica Erem., depending on the stock at average in 2017 2018 , mass. $\%$ in the ash.

\begin{tabular}{|c|c|c|c|c|c|c|c|c|c|c|c|c|}
\hline Elements & $\mathbf{K u}$ & anskay & komet: & ock & & & & Naide & a/stock & & & \\
\hline & $\stackrel{m}{\ddot{g}}$ & 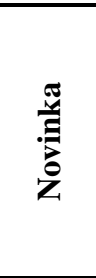 & $\begin{array}{l}\frac{1}{2} \\
\frac{1}{2} \\
\frac{1}{0}\end{array}$ & 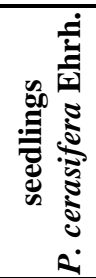 & 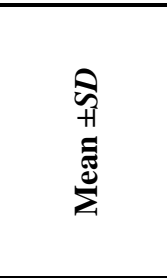 & 氧 & $\stackrel{m}{\frac{m}{2}}$ & 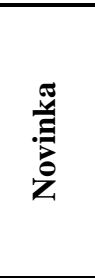 & $\frac{n}{1}$ & 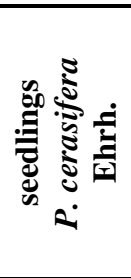 & 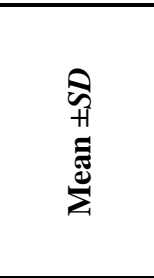 & : \\
\hline $\mathbf{K}$ & 25.21 & 27.48 & 21.19 & 19.12 & $23.25 \pm 3.79$ & 16.29 & 23.45 & 22.09 & 18.67 & 24.98 & $22.30 \pm 2.7$ & 12.07 \\
\hline $\mathbf{P}$ & 4.72 & 6.39 & 3.36 & 3.35 & $4.46 \pm 1.44$ & 32.41 & 3.38 & 4.70 & 3.78 & 5.15 & $4.25 \pm 0.8$ & 19.10 \\
\hline $\mathbf{C a}$ & 1.16 & 1.45 & 1.13 & 1.24 & $1.25 \pm 0.14$ & 11.46 & 0.39 & 1.20 & 1.85 & 1.26 & $1.18 \pm 0.6$ & 20.88 \\
\hline Mo & 1.36 & 1.11 & 0.96 & 0.45 & $0.97 \pm 0.38$ & 39.40 & 0.52 & 1.42 & 1.96 & 1.28 & $1.29 \pm 0.5$ & 45.78 \\
\hline Mg & 1.71 & 1.78 & 1.26 & 1.41 & $1.53 \pm 0.24$ & 15.47 & 2.34 & 1.81 & 1.11 & 2.43 & $1.92 \pm 0.6$ & 31.52 \\
\hline $\mathbf{S}$ & 0.52 & 0.78 & 0.52 & 0.52 & $0.59 \pm 0.13$ & 21.88 & 0.23 & 0.64 & 0.59 & 0.41 & $0.12 \pm 0.2$ & 40.77 \\
\hline $\mathbf{S i}$ & 0.11 & 0.18 & 0.21 & 0.23 & $0.18 \pm 0.05$ & 29.86 & 0.09 & 0.06 & 0.12 & 0.22 & $0.61 \pm 0.1$ & 36.80 \\
\hline $\mathrm{Fe}$ & 0.25 & 0.26 & 0.18 & 0.09 & $0.15 \pm 0.46$ & 32.43 & 0.11 & 0.15 & 0.07 & 0.26 & $0.07 \pm 0.1$ & 36.77 \\
\hline Mn & 0.08 & 0.11 & - & 0.08 & $0.06 \pm 0.08$ & 39.54 & 0.01 & 0.08 & 0.04 & 0.13 & $0.47 \pm 0.1$ & 41.39 \\
\hline $\mathrm{Cu}$ & 0.54 & 0.42 & 0.97 & 0.68 & $0.67 \pm 0.31$ & 40.03 & 0.19 & 0.59 & 0.79 & 0.28 & $0.23 \pm 0.3$ & 40.55 \\
\hline $\mathbf{N i}$ & 0.21 & 0.39 & 0.31 & 0.19 & $0.24 \pm 0.15$ & 36.17 & 0.23 & 0.39 & 0.25 & 0.07 & $0.0 .14 \pm 0.1$ & 35.68 \\
\hline$\sum$ & 48.0 & 51.1 & 52.7 & 59.4 & & & 59.05 & 55.9 & 59.0 & 58.2 & & \\
\hline
\end{tabular}

Note: Results represent mean values $(\mathrm{n}=3) \pm S D$.

The proportion of the rest elements is not more than 1 mass $\%$. The coefficient of variation of elements in the ash plum Kubanskaya kometa / stock ranges from $15.47 \%$ $(\mathrm{Mg})$ to $40.03 \%(\mathrm{Cu})$; Naidena/stock ranges from $12.07 \%$ $(\mathrm{K})$ to $40.77 \% \quad(\mathrm{~S})$, which indicates the relative homogeneity of the data. The average values of the coefficients of variation in the ash plum Kubanskaya kometa / stock were found in the elements S (21.88\%) end Si (29.86\%); in the ash plum Naidena/stock - In the elements $\mathrm{Ca}(20.88 \%)$ and $\mathrm{Mg}(31.52 \%)$. The maximum value of the elements sum was determined in the fruits of scions Kubanskaya kometa

and Naidena on the stock seedlings P.cerasifera Ehrh.

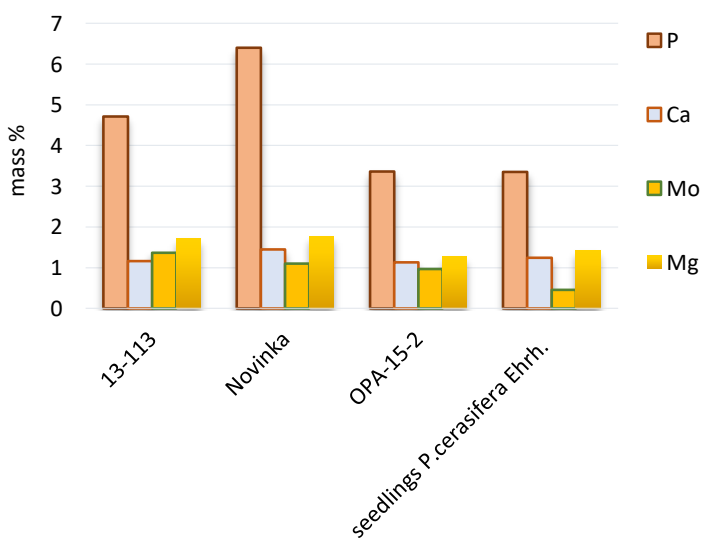

Figure 7 The comparative content of macrolements in the plum fruits ash of scion Kubanskaya kometa on different stocks.
(59.4 and 58.2) and in the scion-stock combination Naidena/OPA-15-2 (59.0) mass \% respectively. At average the maximum value of $\mathrm{K}, \mathrm{P}, \mathrm{Ca}, \mathrm{Mo}, \mathrm{S}, \mathrm{Cu}$ and $\mathrm{Fe}$ is found in the plum fruits of scion Kubanskaya kometa in comparison with the value of $\mathrm{Mg}$ which is on $37 \%$ higher in the scion Naidena. The regularities of the elements content in the ash of both scions on the stocks is identical to the necessary microelements for the human health (Figure 7, 8).

The content of macronutrients in plum fruits is considered in the article (Ertekina et al., 2006).

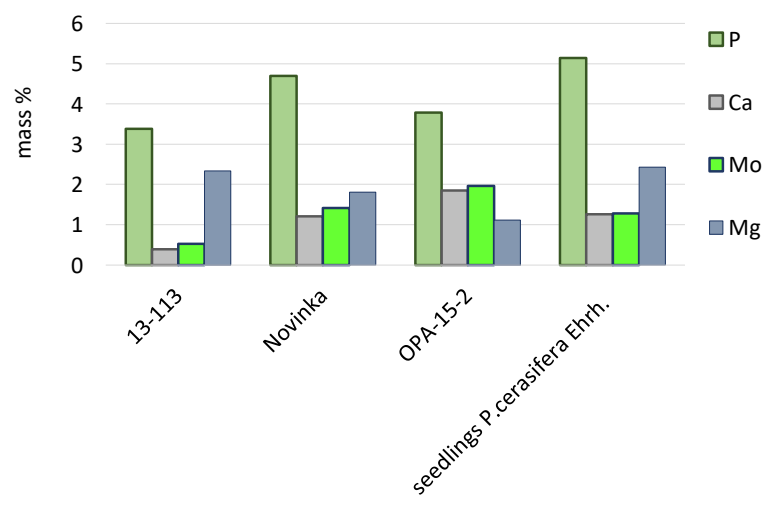

Figure 8 The comparative content of macrolements in the plum fruits ash of scion Naidena on different stocks 


\section{CONCLUSION}

In the present paper the main focus was given to the study of the essential biochemical parameters that characterize the nutritional and dietic value of plum fruits (Prunus rossica Erem.) of different scion-stock combinations. As the result of the researches the stock influence on the trees productivity, the plum fruits (Prunus rossica Erem.) weight and chemical composition was identified and the limits of soluble solids, sugars and ascorbic acid content variation depending on the used scion/stock combinations were determined. Under the stock OPA-15-2 influence higher content of soluble solids, sugars and ascorbic acid accumulated in the fruits. While grafting on alycha seedlings the reduction of the parameters under study was observed. Using the data of the field and laboratory researches the conclusion can be made that the optimal stock for scions Kubanskaya kometa and Naidena is OPA-15-2 may be a better solution to achieve higher yields and better fruit. The results received while working at this paper give new information about the stock influence on the biochemical characteristics of the scions.

\section{REFERENCES}

Agbede, J. O., Ibitoye, A. A. 2007. Chemical composition of black plum (Vitex doniana): an under-utilized fruit. $J$. of Food, Agriculture \& Environment, vol. 5, no. 2, p. 95-96.

Brand-Williams, W., Cuvelier, M. E., Berset, C. 1995. Use of a free radical method to evaluate antioxidant activity. Lebensmittel-Wissenschaft und-Technologie, vol. 28, no. 1, p. 25-30. https://doi.org/10.1016/S0023-6438(95)80008-5

Dekena, D., Poukh, A.V., Kahu, K., Laugale, V., Alsina, I. 2017. Influence of rootstocks on plum productivity in different growing regions. Proceeding of the Latvian Academy of Sciences, vol. 71, no. 3, p. 233-236. https://doi.org/10.1515/prolas-2017-0039

Eremin, G.V. 2003. Plum and alycha. Kharkov : Folio; M: LLC "Izdvo AST", 302 p. ISBN 966-0318-79-0 (in Russian)

Ermakov, A. I., Arasimovich, V. V., Jarosh, N. P. 1987. The methods of the plants biochemical researches. Leningrad : Agropromizdat, 430 p. (in Russian)

Ertekina, C., Gozlekci, S.,Kabasa, O., Sonmez, S., Akincia, I. 2006. Some physical, pomological and nutritional properties of two plum (Prunus domestica L.). Journal of Food Engineering, vol. 75, no. 4, p. 508-514. https://doi.org/10.1016/j.jfoodeng.2005.04.034

Erturka, Y., Ercislib, S., Tosun, M. 2009. Physico-chemical characteristics of wild plum fruits (Prunus spinosa L.). International Journal of Plant Production, vol. 3. no 3. p. 8992.

Gardner, P. T., White, T. A. C., McPhail, D. B., Duthie, G. G. 2000. The relative contributions of vitamin C, carotenoids and phenolics to the antioxidant potential of fruit juices. Food Chemistry, vol. 68, no. 4, p. 471-474. https://doi.org/10.1016/S0308-8146(99)00225-3

Gil, M. G., Tomas-Barberan, F. A., Hess-Pierce, B., Kader, A. A. 2002. Vitamin C Contents of Nectarine, Peach, and Plum Cultivars from California. J. Agric. Food Chem., vol. 50, p. 4976-4982. https://doi.org/10.1021/jf020136b

Grzyb, Z. S., Sitarek, M., Kozinski, B. 1998. Effect of different rootstocks on growth, yield and fruit quality of four plum cultivars (in Central of Poland). Acta Hortic., vol. 478, p. 239-242. https://doi.org/10.17660/ActaHortic.1998.478.37
Hatton, R. G., Amos, J., Witt, A. W., Hoblyn, T. N. 2015. Plum rootstocks; their varieties. propagation. and influence upon cultivated varieties worked thereon. J. of Pomology and Horticultural Science, vol. 7, no. 1, p. 63-99. https://doi.org/10.1080/03683621.1928.11513332

Imeh, U., Khokhar, S. 2002. Distribution of conjugated and free phenolsin fruits: antioxidant activity and cultivar variations. J. Agric. Food Chem., vol. 50, no. 22, p. 63016306. https://doi.org/10.1021/jf020342j

Kalt, W., Forney, C. F., Martin, A., Prior, R. L. 1999. Antioxidant capacity, vitamin C, phenolics, and anthocyanins after fresh storage of small fruits. Journal of Agricultural and Food Chemistry, vol. 47, no. 11, p. 4638-4644. https://doi.org/10.1021/jf990266t

Kukurová, K., Constantin, O. E., Dubová, Z., Tobolková, B., Suhaj, M., Nystazou, Z., Rapeanu, G., Ciesarová, Z. 2015. Acrylamide content and antioxidant capacity in thermally processed fruit products. Potravinarstvo Slovak Journal of Food Sciences, vol. 9, no. 1, p. 90-94. https://doi.org/10.5219/423

Kulichová, J., Híc, P., Balík, J., Tř́iska, J., Vrchotová, N., Houška, M. 2016. The possibilities of increasing lignan content in food. Potravinarstvo Slovak Journal of Food Sciences, vol. 10, no. 1, p. 649-655. https://doi.org/10.5219/675

Magyar, L., Hrotkó, K. 2006. Growth and productivity of plum cultivars on various rootstocks in intensive orchard. International Journal of Horticultural Science, vol. 12, no. 3, p. 77-81. https://doi.org/10.31421/IJHS/12/3/663

Milošević, T., Milošević, N. 2012. The physical and chemical attributes of plum influenced by rootstock. Acta Alimentaria, vol. 41, no. 3, p. 293-303. https://doi.org/10.1556/AAlim.41.2012.3.1

Milosevic, T., Milosevic, N., Glisic, I. 2011. Influence of Stock on the Early Tree Growth. Yield and Fruit Quality Traits of Apricot (Prunus armeniaca L.). J. of Agricultural Sciences, vol. $\quad 17, \quad$ p. $167-176$. https://doi.org/10.1501/Tarimbil_0000001169

Motyleva, S. M., Kulikov, I. M., Marchenko, L. A. 2017. EDS Analysis for Fruit Prunus Elemental Composition Determination. Materials Science Forum, vol. 888, p. 314318. https://doi.org/10.4028/www.scientific.net/MSF.888.314

Motyleva, S. M., Simonov, V. S. Kulikov, I. M., Mertvischeva, M. E. 2017. Pomological and biochemical peculiarities of plum fruits. Journal of the Russian Agricultural Science, vol. 2, p. 37-42. (in Russian)

Najafabad, A. M., Jamei R. 2014. Free radical scavenging capacity and antioxidant activity of methanolic and ethanolic extracts of plum (Prunus domestica L.) in both fresh and dried samples. Avicenna J. Phytomed., vol. 4, no. 5, p. 343353.

Ratoa, A. E., Agulheiroa, A. C., Barrosoa, J. M., Riquelmeb, F. 2008. Soil and rootstock influence on fruit quality of plums (Prunus domestica L.). Scientia Horticulturae, vol. 118, no. 3, p. 218-222. https://doi.org/10.1016/j.scienta.2008.06.013

Stan, M., Soran, M. L., Marutoiu, C. 2014. Extraction and HPLC Determination of the Ascorbic Acid Content of Three Indigenous Spice Plants. Journal of Analytical Chemistry, vol, 69, no. $10, \quad$ p. $998-1002$. https://doi.org/10.1134/S106193481410013X

Świerczyński, S., Stachowiak, A. 2009.The usefulness of two rootstocks for some plum cultivars. J. of Fruit and Ornamental Plant Research, vol. 17, no. 2, p. 63-71. 
Upadysheva, G. Y. 2017. Efficiency of propagation of the cherry plum hybrid on clonal rootstocks in the Moscow area. J. Horticultureand viticulture, vol. 4, p. 25-29. https://doi.org/10.18454/VSTISP.2017.4.6841

Upadysheva, G. Y., Motyleva, S. M. 2019. Change in the biochemical composition of alycha hybrid of the leaves under influence of the stock. In $V$ International scientific and methodological conference. Role of physiology and biochemistry in introduction and selection of agricultural plants. Moskva : PFUR, p. 185-189. ISBN 978-5-209-093585.

Upadysheva, G., Motyleva, S., Kulikov, I., Medvedev, S., Mertvisheva, M. 2018. Biochemical composition of sweet cherry (Prunus avium L.) fruit depending on the scion-stock combinacions. Potravinarstvo Slovak Journal of Food Sciences, vol. 12, no. 1, p. 533-538. https://doi.org/10.5219/923

\section{Contact address:}

*Svetlana Motyleva, PhD (Ag), assistant professor, Head of the Laboratory of Physiology and Biochemistry of Federal State Budgetary Scientific Institution "All-Russian Horticultural Institute for Breeding, Agrotechnology and Nursery“ 115598, Russia, Moscow, Zagorevskaj 4, phone: +7 (910) 205-27-10,

E-mail: motyleva_svetlana@mail.ru

ORCID: https://orcid.org/0000-0003-3399-1968

Galina Upadysheva, PhD (Ag) PhD (Ag), leading researcher of Federal State Budgetary Scientific Institution "All-Russian Horticultural Institute for Breeding, Agrotechnology and Nursery“ 115598, Russia, Moscow, Zagorevskaj 4, phone: +7 (495) 329-51-66,

E-mail: upad64@mail.ru

ORCID: https://orcid.org/0000-0002-9547-9178
Ivan Kulikov, Doctor of Economics, Prof., academician of RAS, Director of the Institute Federal State Budgetary Scientific Institution "All-Russian Horticultural Institute for Breeding, Agrotechnology and Nursery“ 115598, Russia, Moscow, Zagorevskaj 4, phone: +7 (495) 329-5166,

E-mail: vstisp@ vstisp.org

ORCID: https://orcid.org/0000-0001-8071-0931

Mikhail Upadyshev, Doctor of Agricultural Sciences, Corresponding Member of RAS, Head of the Laboratory of Virology «All-Russian Horticultural Institute for Breeding, Agrotechnology and Nursery»" 115598, Russia, Moscow, Zagorevskaj 4, phone: +7 (495) 329-51-66,

E-mail: upad8@mail.ru

ORCID: https://orcid.org/0000-0003-1069-3771

Sergei Medvedev, Doctor of Economics, Prof., Head of the center of the gene pool and bioresource of plants, of Federal State Budgetary Scientific Institution "All-Russian Horticultural Institute for Breeding, Agrotechnology and Nursery“ 115598, Russia, Moscow, Zagorevskaj 4, phone: +7 (495) 329-51-66,

E-mail: mos_vstisp@mail.ru

ORCID: https://orcid.org/0000-0002-4747-9835

Dariya Panischeva, graduate student of the Laboratory of Physiology and Biochemistry of Federal State Budgetary Scientific Institution "All-Russian Horticultural Institute for Breeding, Agrotechnology and Nursery" 115598, Russia, Moscow, Zagorevskaj 4, phone: +7 (977) 994-7716 , E-mail: pani-darya@yandex.ru

ORCID: https://orcid.org/0000-0002-5-0548-0192

Corresponding author: * 